\title{
"It Felt Good to Be Included": A Mixed-Methods Study of Pre-Kindergarten Teachers' Experiences with Professional Learning
}

\author{
Kim Stevens Barker ${ }^{1}$ (1) Do-Hong Kim² ${ }^{2}$ Elizabeth Pendergraft ${ }^{1}$
}

Accepted: 8 March 2021 / Published online: 1 April 2021

(c) The Author(s), under exclusive licence to Springer Nature B.V. 2021

\begin{abstract}
This article reports findings from a study to investigate the efficacy beliefs, experiences, and instructional practices of prekindergarten (pre-k) teachers from a high-need district who engaged in collaborative professional learning experiences provided by a partner university. The study also examined language and literacy instruction for children in their pre-k classrooms. The professional learning occurred as part of a project to support pre-k teachers within the district and to boost teaching effectiveness. Researchers employed a mixed methods approach to investigate how pre-k teacher participants (a) perceived their efficacy as teachers; (b) experienced early literacy-focused professional learning; and (c) approached literacy teaching within their classrooms. Analysis of three years of data reveal alignment between participants' sense of efficacy and instructional strengths and areas for growth both self-reported and observed. Additionally, participants echoed feelings of exclusion from most professional learning experiences and offered insight into considerations for designing and delivering professional learning opportunities to effectively support pre-k teachers' literacy instructional practices.
\end{abstract}

Keywords Professional learning $\cdot$ Pre-kindergarten $\cdot$ Early literacy $\cdot$ Teacher efficacy $\cdot$ School-university partnerships

The positive effects of quality pre-kindergarten (pre-k) learning experiences on subsequent academic and life outcomes for children from underserved communities are welldocumented (Heckman, 2011). High-quality pre-k programs that yield the greatest gains for children include teachers who engage their young learners with rigorous, developmentally appropriate pedagogical strategies at the highest levels. This kind of instruction is developed and supported when teachers engage in intensive professional learning (PL) experiences (Pianta \& Hamre, 2020).

When we, as faculty of a university teacher education unit, collaborated with administrators of a high-need partner school district to design a literacy-focused program to

Kim Stevens Barker

kbarker@augusta.edu

Do-Hong Kim

dhkim@wayne.edu

Elizabeth Pendergraft

bpendergraft@augusta.edu

1 Augusta University, 1120 15th Street, UH-366, Augusta, GA 30912, USA

2 Wayne State University, 441 Education Bldg., Detroit, MI 48202, USA support early learners in the district, support for pre-k teachers emerged as an area of priority. District officials noted that pre-k teachers' lower pay rate and feelings that they were "left out of everything" contributed to the district's high turnover rate among pre-k teachers, and they sought innovative approaches to boost their pre-k teachers' instructional skills and morale to increase retention. Together, we designed a new pre-k strand at the university's annual education conference with the goals of supporting pre-k teachers' efficacy through the delivery of early literacy-focused PL to boost instructional practices. In order to learn how university-sponsored PL experiences might impact pre-k teachers' efficacy and instructional practices, and how the collaboration might best provide PL for pre-k teachers in the future, we asked the following questions:

(1) How do pre-k teacher participants perceive their efficacy as teachers?

(2) How do pre-k teacher participants experience early literacy-focused PL?

(3) How do pre-k teacher participants approach language and literacy teaching within their classrooms? 
This study reports findings from both qualitative and quantitative data collected through surveys, focus group interviews, and classroom observations that highlight the participating pre-k teachers' feelings of efficacy, their experiences engaging in PL, and their classroom literacy instruction.

\section{Conceptual Framework}

This study draws on the extensive research base that supports teaching efficacy as a key to developing and delivering high-quality learning experiences. Self-efficacy is a person's perceptions of their own capabilities to learn or complete a specific task given the skills they possess (Bandura, 1977, 1997; Pajares, 1996). According to social cognitive theory, human beings have to be proactive in their development and use their own skills to impact their environment. Key to this view of human agency is self-efficacy (Parajes, 2009). Teacher efficacy impacts behaviors, goals, aspirations, persistence, openness to new ideas, and energy levels, all factors important to teachers' abilities to teach at the highest levels and to persist in challenging school contexts (TschannonMoran \& Woolfolk Hoy, 2001). Understanding pre-k teachers' feelings of efficacy was foundational to the design and implementation of PL within this study, since we knew that our participants' previous experiences with PL had influenced and would continue to influence their sense of agency as teachers.

Self-efficacy is foundational for effective teaching, and effective teaching is the cornerstone of pre-k experiences that are considered high quality (Farran, 2020). High quality early learning experiences are particularly important for children from low-income homes, since they may come to school with fewer formal early learning experiences and with greater gaps in language and literacy development (Burchinal, 2018). While definitions of quality in early education vary, recent research has focused on interactions between teacher and child as key to assessing and improving the quality of learning experiences, and PL has proven to improve such interactions (Eadie et al., 2019).

\section{Context}

This pre-k PL collaboration was developed by faculty of the teacher education department of a mid-sized university located in a small city in the southeastern United States along with administrators of a high-need partner school district. More than half of the students in the district were economically disadvantaged, and more than one third were identified as living in poverty. Literacy achievement lagged in the district, with only $33 \%$ of 3rd grade students and 39\% of 4th grade students reading on grade level. The PL was focused on early literacy instruction through the mechanism of a free day-long university education conference that had been targeted to K-12 educators for more than two decades.

University and district staff collaborated to plan conference experiences each year of the study to support not only the pre-k teachers' feelings of inclusion within the broader educational community, but also to emphasize special recognition and support for their contribution to K-12 student learning. Each year, pre-k teacher conference attendees received an "Early Educator" ribbon to attach to their conference name tags, and they were recognized at the opening plenary session for their foundational impact on student learning.

\section{Methods}

\section{Participants}

A total of 29 pre-k teachers attended the literacy-focused PL during the university education conference across the 3 years of the study. Seventeen of the 53 pre-k teachers in the district attended the 2018 conference; 17 of 56 pre-k teachers attended the 2019 conference; and 11 of 54 pre-k teachers attended the 2020 conference. Table 1 shows the number of participants by year, the number of participants

Table 1 Demographic characteristics

\begin{tabular}{llll}
\hline & 2018 & 2019 & 2020 \\
& $n$ & $n$ & $n$ \\
\hline Total participants & 17 & 17 & 11 \\
New participants & 17 & 10 & 5 \\
Returning partici- & 0 & 7 & 6 \\
pants & & & \\
Observations & 13 & 10 & None (COVID-19) \\
Survey data & 17 & 17 & 11 \\
Focus group data & 0 & 6 & 11 \\
& $n(\%)$ & $n(\%)$ & $n(\%)$ \\
Gender & & & \\
Female & $17(100)$ & $17(100)$ & $11(100)$ \\
Race/Ethnicity & & & \\
African American & $11(64.7)$ & $13(76.5)$ & $5(45.5)$ \\
White & $6(35.3)$ & $4(23.5)$ & $5(45.5)$ \\
Unknown & & & $1(1)$ \\
Education & & & \\
Master/specialist & $6(35.3)$ & $6(35.5)$ & $4(36.4)$ \\
Bachelor & $11(64.7)$ & $10(58.8)$ & $7(63.6)$ \\
Associate & & $1(5.7)$ & \\
& $M(S D)$ & $M(S D)$ & $M(S D)$ \\
Number of years of & $4.53(4.64)$ & $7.31(5.85)$ & $6.68(5.49)$ \\
teaching & & & \\
\hline
\end{tabular}


who repeated attendance, and the demographic characteristics reported by participants.

\section{Procedures}

During the first two years of the study (2018-2019), the school district pre-k coordinator invited all pre-k teachers by email to attend the conference. In 2020, a university faculty member emailed all of the pre-k teachers personally to invite them to attend.

All attendees completed a pre-conference survey that included demographic information and the Teachers' Sense of Efficacy Scale (Appendix A; Tschannen-Moran \& Woolfolk Hoy, 1998) and a post-conference evaluation that consisted of three Likert-type questions and three open-ended questions asking for feedback on the PL and suggestions for future PL topics (Appendix B).

PL activities at the 2018 conference included a session focused on incorporating hands-on early literacy strategies to develop letter recognition and sound segmentation, a picture book read-aloud demonstration, a session on promoting parent engagement, and a freely chosen session where teachers selected from any of the conference concurrent sections. Feedback from the 2018 attendees indicated their interest in incorporating literacy into science and social studies and in supporting early writing.

The 2019 PL sessions were developed from the 2018 feedback requesting support for engaging writing activities in the content areas. Teacher educators from another university who specialized in the use of paired fiction and nonfiction texts to support early writing facilitated two morning sessions on the topics, with attendees having the afternoon free to select from other concurrent conference sessions. Pre- $k$ attendees received make-and-take classroom resources as well as literacy kits that included paired and bilingual texts, writing supplies, and classroom mailboxes.

The 2020 PL activities were based on feedback gathered from the 2019 conference. Attendees again requested additional support for writing in the content areas, and further suggested PL for tying writing activities to state standards for early learning. Focus group data revealed that participants valued the expertise of their colleagues and preferred to learn from one another. For this reason, two teachers from the district who participated in and were recommended during the interview were invited to present on aligning engaging writing activities to the state early learning standards. The pair presented morning and afternoon sessions. University faculty presented findings from the ongoing study and facilitated a group jigsaw activity to explore the use of books and book reading in the classroom.

Each year, participants completed an initial survey that included demographic information and an efficacy scale. During the last session of each conference, participants completed a post-conference evaluation. During the 2019 and 2020 conferences, attendees were invited to participate in focus group interviews. After the 2018 and 2019 conferences, researchers visited classrooms of new participants to conduct observations. New teachers from the 2020 conference were not observed due to COVID-19 restrictions.

\section{Instruments}

Multiple measures were used to document key variables associated with the implementation of the program and to examine its relation to pre-k teachers' sense of efficacy, their experiences with PL, and their literacy teaching practices.

The Teachers' Sense of Efficacy Scale (TSES) includes 12 items and is measured on a 9-point scale, ranging from 1 (Nothing) to 9 (A great deal) (Appendix A; TschannenMoran \& Woolfolk Hoy, 1998). There are four items in each of the following three factors: instructional strategies, engagement, and classroom management. Previous studies have reported strong internal consistency reliability and validity evidence for TSES as Cronbach's alpha values ranged from 0.92 to 0.95 for the full scale, and from 0.86 to 0.90 for the three subscales, indicating great internal consistency reliability (Tschannen-Moran \& Woolfolk Hoy, 2007). Results of factor analyses supported both a three-factor solution and a single factor solution, indicating that both the total score and the subscale scores can be used to assess teacher self-efficacy. The TSES total scores were positively related to other existing measures of teacher efficacy, providing evidence for construct validity (Tschannen-Moran \& Woolfolk Hoy, 2001). The TSES was also validated in five countries and demonstrated strong measurement invariance (Klassen et al., 2009). The TSES scores were strongly related to teacher job satisfaction and a similar pattern of the relationship was found across settings, providing further evidence for cross-cultural validity (Klassen et al., 2009).

The Early Language and Literacy Observation (ELLCO) Toolkit was used to guide classroom observations of materials and practices related to early language and literacy learning. The observation section rates classrooms language and literacy environments along 19 holistic dimensions using a 5-point rating scale, with 1 being deficient, three being basic, and five being exemplary (Smith et al., 2002). The ELLCO consists of five sections (Classroom Structure, Curriculum, Language Environment, Books and Book Reading, and Print and Early Writing) that are summed to create two subscale scores (General Classroom Environment and Language and Literacy). The ELLCO showed good reliability evidence: An average interrater reliability was 0.74 and Cronbach's alphas ranged from 0.723 to 0.922 for the five sections and two subscales (Smith et al., 2012). It also provided evidence for both convergent and divergent validity (Smith et al., 2012). 
The focus group interviews occurred during the 2019 and 2020 conferences and lasted for about an hour. The questions that guided the interviews related to: (a) work-related feelings; (b) literacy teaching experiences during the project; and (c) recommendations for future partnership activities (Appendix C). Focus group data provided insight into research questions.

\section{Data Analysis}

Descriptive statistics were used to summarize the data. Cohen's d effect sizes for repeated measures (Cohen, 1988) were calculated to compare the 2018 and 2019 self-efficacy results of the both-year participants. Pearson correlation coefficient was also calculated to examine a correlation between the 2018 and 2019 self-efficacy scores.

The focus group interviews were audio-recorded and transcribed. The interviews were analyzed line-by-line using first round open-coding, followed by thematic coding (Creswell, 2013). The transcripts and analysis were sent to participants for member checking to confirm identified themes.

\section{Results}

\section{Teachers' Sense of Efficacy}

The results showed that, on average, participants had a strong sense of efficacy beliefs in teaching in all three years, $2018(M=7.34, S D=1.14), 2019(M=7.15, S D=0.89)$, and $2020(M=7.99, S D=1.03)$. As shown in Table 2, across all three years, question 3 (get students to believe they can do well in school work) showed the highest mean score. Question 3 pertains to efficacy for engagement. The lowest mean score was found for question 10 (provide an alternative explanation or example when students are confused) in 2018, question 5 (craft good questions for your students) in 2019, and question 7 in 2020 (calm a student who is disruptive or noisy). Both questions 5 and10 pertain to efficacy for instructional strategies and question 7 pertains to efficacy for classroom management. Participants of the 2020 conference showed higher levels of self-efficacy than those of the 2018 and 2019 conferences. It is noted that six of 11 participants in 2020 also attended either the 2018 or 2019 conference, and one participant attended all three years.

\section{Post-Conference Evaluation}

For all three years, respondents $(n=16$ in $2018 ; n=17$ in $2019 ; n=11$ in 2020) either agreed or strongly agreed that the PL was helpful for their classroom instruction, that their students would benefit from the PL, and that they would be interested in attending the conference again. Qualitative comments were analyzed and categorized for two questions from post-conference evaluation addressing: (a) the most helpful new knowledge from the PL; and (b) topics for future PL. Across all three years, respondents emphasized an appreciation for pre-k focused PL and for the opportunity to learn from and with other pre-k teachers. Literacy topics they found helpful were: ideas for read-alouds, handson phonics, oral language development, emergent writing, and literacy across content areas. Ideas for future PL topics

Table 2 Descriptive statistics of the teachers' sense of efficacy scale scores

\begin{tabular}{|c|c|c|c|c|c|c|c|}
\hline \multirow[t]{2}{*}{ Factor } & \multirow[t]{2}{*}{ Question } & \multicolumn{2}{|l|}{2018} & \multicolumn{2}{|l|}{2019} & \multicolumn{2}{|l|}{2020} \\
\hline & & Mean & $S D$ & Mean & $S D$ & Mean & $S D$ \\
\hline Classroom management & 1. How much can you do to control disruptive behavior in the classroom? & 7.53 & 1.88 & 6.94 & 1.2 & 8.33 & 0.82 \\
\hline Engagement & $\begin{array}{l}\text { 2. How much can you do to motivate students who show low interest in } \\
\text { school work? }\end{array}$ & 7.24 & 1.48 & 7.65 & 1.22 & 8.83 & 0.41 \\
\hline Engagement & $\begin{array}{l}\text { 3. How much can you do to get students to believe they can do well in school } \\
\text { work? }\end{array}$ & 7.82 & 1.19 & 7.94 & 1.03 & 9.00 & 0 \\
\hline Engagement & 4. How much can you do to help your students value learning? & 7.71 & 1.16 & 7.59 & 1.00 & 8.33 & 0.82 \\
\hline Instructional strategies & 5. To what extent can you craft good questions for your students? & 7.18 & 1.38 & 6.41 & 1.12 & 8.17 & 0.75 \\
\hline Classroom management & 6. How much can you do to get children to follow classroom rules? & 7.47 & 1.23 & 6.88 & 1.27 & 8.17 & 0.41 \\
\hline Classroom management & 7. How much can you do to calm a student who is disruptive or noisy? & 7.29 & 1.72 & 6.76 & 1.03 & 7.17 & 0.98 \\
\hline Classroom management & $\begin{array}{l}\text { 8. How well can you establish a classroom management system with each } \\
\text { group of students? }\end{array}$ & 7.24 & 1.64 & 6.94 & 1.34 & 8.00 & 0.63 \\
\hline Instructional strategies & 9. How much can you use a variety of assessment strategies? & 7.00 & 1.66 & 6.82 & 1.38 & 8.17 & 0.41 \\
\hline Instructional strategies & $\begin{array}{l}\text { 10. To what extent can you provide an alternative explanation or example } \\
\text { when students are confused? }\end{array}$ & 6.94 & 1.09 & 7.29 & 1.16 & 7.67 & 1.03 \\
\hline Engagement & $\begin{array}{l}\text { 11. How much can you assist families in helping their children do well in } \\
\text { school? }\end{array}$ & 7.41 & 1.37 & 7.41 & 1.23 & 7.83 & 1.47 \\
\hline Instructional strategies & 12. How well can you implement alternative strategies in your classroom? & 7.24 & 1.35 & 7.12 & 1.11 & 7.83 & 1.17 \\
\hline
\end{tabular}


included: additional literacy strategies, support for integrating literacy into the state learning standards, and classroom management.

\section{Classroom Observations}

Of 17 teachers who attended the 2018 conference, 13 teachers' classrooms were observed using the ELLCO. Of the total of 17 teachers attending the 2019 conference, 10 teachers attended the conference for the first time and were subsequently observed using the ELLCO. New teachers attending the 2020 conference were not observed due to COVID-19 restrictions. As shown in Table 3, for 2018 and 2019, Classroom Structure had the highest score and Print and Early Writing had the lowest score. The General Classroom Environment subscale score was higher than that of Language and Literacy subscale (Table 3). Of the 19 dimensions, Item 4, Personnel showed the highest mean score and Item 18, Support for Children's Writing showed the lowest mean score (Table 4).

\section{Returning Teachers' Sense of Efficacy}

A total of seven pre-k teachers from the partner district attended both the 2018 and 2019 conferences. The average number of years of teaching experience for returning teachers was $5.86(S D=6.96)$, which was higher than the oneyear participants' average $(M=3.50, S D=1.52)$. On average, participants' levels of perceived efficacy did not change from 2018 to $2019(M=7.19, S D=1.45$ for $2018 ; M=7.19$, $S D=0.85$ for 2019$)$. There was a very strong correlation between the 2018 and 2019 self-efficacy scores $(r=0.95)$.

As shown in Table 5, teachers' efficacy beliefs increased in questions $2,7,8,9,10$, and 12 , the largest increase being in question 10 (provide an alternative explanation or example when students are confused). The effect size for question 10 (Cohen's $d=0.81$ ) was considered large. Teachers' efficacy beliefs decreased in questions $1,3,4,5,6$, and 11 , the largest decrease being in question 5 (craft good questions for your students). The effect size for question 5 (Cohen's $d=0.66$ ) was considered medium. Both questions 5 and 10 pertain to efficacy for instructional strategies.

Table 6 shows the teacher self-efficacy results in 2020 . For most of the questions, the teachers who attended either the 2018 or 2019 conferences and returned in 2020 showed higher levels of self-efficacy than those who attended the conference for the first time (new teachers), with the largest difference being in question 8 (establish a classroom management system with each group of students). For questions $4,5,7$, and 10 , the new teachers showed slightly higher levels of self-efficacy.

\section{Returning Teachers' Classroom Observations}

The seven returning teachers were observed between the 2018 and 2019 conferences. As shown in Table 3, Classroom Structure had the highest score. Print and Early Writing had the lowest score. The item-level result (Table 4) showed that Item 4, Personnel, showed the highest mean score and Item 18, Support for Children's Writing, showed the lowest mean score. The returning teachers scored higher in all areas of ELLCO as compared to the teachers who attended the conference for the first time in 2019 (Tables 3 and 4).

\section{Focus Group Interviews}

Six teachers participated in a focus group interview during the 2019 conference. The interview was announced prior to the morning session and took place during a working lunch after participants traveled to the designated conference location to pick up boxed lunches and then returned to the session location. All of the teachers who chose to participate in the focus group identified as African American and had 3-5 years of experience teaching pre-k within the school district. Four of the teachers had attended the conference in 2018 , and 2 were new to the conference.

The researchers scheduled the 2020 focus group interview as a session immediately following the teachers' return from
Table 3 Teachers' ELLCO results-subscales

\begin{tabular}{|c|c|c|c|c|c|c|c|c|}
\hline \multirow[b]{2}{*}{ Question } & \multicolumn{2}{|c|}{$\begin{array}{l}2018 \& 2019 \\
(n=23)\end{array}$} & \multicolumn{2}{|c|}{$2018(n=13)$} & \multicolumn{2}{|c|}{$\begin{array}{l}2019 \text { New } \\
\text { teachers } \\
(n=10)\end{array}$} & \multicolumn{2}{|c|}{$\begin{array}{l}\text { Returning } \\
\text { teachers } \\
(\mathrm{n}=7)\end{array}$} \\
\hline & Mean & $S D$ & Mean & $S D$ & Mean & $S D$ & Mean & $S D$ \\
\hline Classroom structure & 3.79 & 0.62 & 4.02 & 0.57 & 3.50 & 0.58 & 4.04 & 0.77 \\
\hline Curriculum & 3.43 & 0.72 & 3.77 & 0.64 & 3.00 & 0.59 & 3.95 & 0.73 \\
\hline Language environment & 3.64 & 0.85 & 3.88 & 0.72 & 3.33 & 0.93 & 3.89 & 0.85 \\
\hline Books and book reading & 3.16 & 0.96 & 3.35 & 0.93 & 2.90 & 0.98 & 3.63 & 0.95 \\
\hline Print and early writing & 3.01 & 0.99 & 3.21 & 0.96 & 2.77 & 1.03 & 3.43 & 0.96 \\
\hline General classroom environment subscale & 3.61 & 0.59 & 3.89 & 0.57 & 3.25 & 0.41 & 3.99 & 0.72 \\
\hline Language and literacy subscale & 3.27 & 0.71 & 3.48 & 0.61 & 3.00 & 0.76 & 3.65 & 0.73 \\
\hline
\end{tabular}


Table 4 Teachers' ELLCO item-level results

\begin{tabular}{|c|c|c|c|c|c|c|c|c|}
\hline \multirow[t]{2}{*}{ Question } & \multicolumn{2}{|c|}{$\begin{array}{l}2018 \& 2019 \\
(\mathrm{n}=23)\end{array}$} & \multicolumn{2}{|c|}{$\begin{array}{l}2018 \\
(n=13)\end{array}$} & \multicolumn{2}{|c|}{$\begin{array}{l}2019 \text { New } \\
\text { teachers } \\
(n=10)\end{array}$} & \multicolumn{2}{|c|}{$\begin{array}{l}2019 \text { Return- } \\
\text { ing teachers } \\
(\mathrm{n}=7)\end{array}$} \\
\hline & Mean & $S D$ & Mean & $S D$ & Mean & $S D$ & Mean & $S D$ \\
\hline \multicolumn{9}{|l|}{ Classroom structure } \\
\hline 1. Organization of the classroom & 3.83 & 0.89 & 3.92 & 0.86 & 3.70 & 0.95 & 4.00 & 0.82 \\
\hline 2. Contents of the classroom & 3.26 & 0.86 & 3.62 & 0.96 & 2.80 & 0.42 & 3.86 & 1.07 \\
\hline 3. Classroom management & 3.65 & 0.98 & 3.92 & 0.86 & 3.30 & 1.06 & 3.71 & 0.95 \\
\hline 4. Personnel & 4.43 & 0.90 & 4.62 & 0.87 & 4.20 & 0.92 & 4.57 & 1.13 \\
\hline \multicolumn{9}{|l|}{ Curriculum } \\
\hline 5. Approaches to curriculum & 3.57 & 1.04 & 4.00 & 0.91 & 3.00 & 0.94 & 4.14 & 0.90 \\
\hline 6. Opportunities for child choice and initiative & 3.35 & 1.03 & 3.38 & 1.12 & 3.30 & 0.95 & 3.29 & 1.38 \\
\hline 7. Recognizing diversity in the classroom & 3.39 & 1.08 & 3.92 & 1.04 & 2.70 & 0.67 & 4.43 & 0.79 \\
\hline \multicolumn{9}{|l|}{ Language environment } \\
\hline 8. Discourse climate & 3.48 & 1.08 & 3.62 & 1.04 & 3.30 & 1.16 & 3.71 & 1.38 \\
\hline 9. Opportunities for extended conversations & 3.52 & 1.04 & 3.69 & 1.03 & 3.30 & 1.06 & 3.57 & 1.27 \\
\hline 10. Efforts to build vocabulary & 3.91 & 1.00 & 4.15 & 0.69 & 3.60 & 1.26 & 4.00 & 0.58 \\
\hline 11. Phonological awareness & 3.65 & 1.03 & 4.08 & 0.76 & 3.10 & 1.10 & 4.29 & 0.49 \\
\hline \multicolumn{9}{|l|}{ Books and book reading } \\
\hline 12. Organization of book area & 3.13 & 0.92 & 3.31 & 0.95 & 2.90 & 0.88 & 3.29 & 0.95 \\
\hline 13. Characteristics of books & 3.13 & 0.97 & 3.23 & 1.01 & 3.00 & 0.94 & 3.43 & 0.79 \\
\hline 14. Books for learning & 3.04 & 1.11 & 3.38 & 1.19 & 2.60 & 0.84 & 3.71 & 0.95 \\
\hline 15. Approaches to book reading & 3.39 & 1.44 & 3.54 & 1.39 & 3.20 & 1.55 & 3.86 & 1.35 \\
\hline 16. Quality of book reading & 3.09 & 1.86 & 3.31 & 1.93 & 2.80 & 1.81 & 3.86 & 1.68 \\
\hline \multicolumn{9}{|l|}{ Print and early writing } \\
\hline 17. Early writing environment & 2.87 & 1.14 & 2.92 & 1.12 & 2.80 & 1.23 & 3.14 & 1.07 \\
\hline 18. Support for children's writing & 2.70 & 1.26 & 2.85 & 1.34 & 2.50 & 1.18 & 3.00 & 1.53 \\
\hline 19. Environmental print & 3.48 & 1.08 & 3.85 & 0.99 & 3.00 & 1.05 & 4.14 & 0.90 \\
\hline
\end{tabular}

Table 5 Self-efficacy results of returning teachers in 2019

\begin{tabular}{|c|c|c|c|c|}
\hline \multirow[t]{2}{*}{ Question } & \multicolumn{2}{|l|}{2018} & \multicolumn{2}{|l|}{2019} \\
\hline & Mean & $S D$ & Mean & $S D$ \\
\hline 1. How much can you do to control disruptive behavior in the classroom? & 7.00 & 2.45 & 6.71 & 1.25 \\
\hline 2. How much can you do to motivate students who show low interest in school work? & 7.57 & 1.90 & 7.86 & 1.21 \\
\hline 3. How much can you do to get students to believe they can do well in school work? & 8.14 & 1.21 & 7.86 & 1.21 \\
\hline 4. How much can you do to help your students value learning? & 8.00 & 1.15 & 7.43 & 0.98 \\
\hline 5. To what extent can you craft good questions for your students? & 6.71 & 1.50 & 5.86 & 1.07 \\
\hline 6. How much can you do to get children to follow classroom rules? & 7.00 & 1.53 & 7.00 & 1.41 \\
\hline 7. How much can you do to calm a student who is disruptive or noisy? & 6.43 & 2.15 & 6.86 & 0.90 \\
\hline 8. How well can you establish a classroom management system with each group of students? & 6.57 & 2.23 & 7.14 & 1.57 \\
\hline 9. How much can you use a variety of assessment strategies? & 7.14 & 2.12 & 7.29 & 1.38 \\
\hline 10. To what extent can you provide an alternative explanation or example when students are confused? & 7.00 & 1.00 & 7.71 & 0.76 \\
\hline 11. How much can you assist families in helping their children do well in school? & 7.71 & 1.11 & 7.29 & 1.25 \\
\hline 12. How well can you implement alternative strategies in your classroom? & 7.00 & 1.41 & 7.29 & 1.11 \\
\hline
\end{tabular}

lunch. All 11 attendees participated in the interview. Six teachers identified as African American, 4 teachers identified as White, and 1 did not identify. Years of experience ranged from a few months to 16 years. Both focus group interviews were conducted in a relaxed setting with participants seated in self-selected small groups.

The interview protocol (see Appendix C) consisted of 5 open-ended questions. Themes that emerged from the data 
Table 6 Self-efficacy results of teachers in 2020

\begin{tabular}{|c|c|c|c|c|}
\hline \multirow[t]{2}{*}{ Question } & \multicolumn{2}{|c|}{$\begin{array}{l}\text { Returning teach- } \\
\operatorname{ers}(n=6)\end{array}$} & \multicolumn{2}{|c|}{$\begin{array}{l}\text { New teachers } \\
(n=5)\end{array}$} \\
\hline & Mean & $S D$ & Mean & $S D$ \\
\hline 1. How much can you do to control disruptive behavior in the classroom? & 8.33 & 0.82 & 7.40 & 2.61 \\
\hline 2. How much can you do to motivate students who show low interest in school work? & 8.83 & 0.41 & 8.20 & 1.79 \\
\hline 3. How much can you do to get students to believe they can do well in school work? & 9.00 & 0.00 & 8.40 & 0.89 \\
\hline 4. How much can you do to help your students value learning? & 8.33 & 0.82 & 8.40 & 0.89 \\
\hline 5. To what extent can you craft good questions for your students? & 8.17 & 0.75 & 8.20 & 1.10 \\
\hline 6. How much can you do to get children to follow classroom rules? & 8.17 & 0.41 & 7.25 & 2.36 \\
\hline 7. How much can you do to calm a student who is disruptive or noisy? & 7.17 & 0.98 & 7.80 & 1.79 \\
\hline 8. How well can you establish a classroom management system with each group of students? & 8.00 & 0.63 & 6.80 & 1.64 \\
\hline 9. How much can you use a variety of assessment strategies? & 8.17 & 0.41 & 7.20 & 2.05 \\
\hline 10. To what extent can you provide an alternative explanation or example when students are confused? & 7.67 & 1.03 & 8.00 & 1.41 \\
\hline 11. How much can you assist families in helping their children do well in school? & 7.83 & 1.47 & 7.20 & 1.48 \\
\hline 12. How well can you implement alternative strategies in your classroom? & 7.83 & 1.17 & 7.40 & 1.67 \\
\hline
\end{tabular}

highlighted participants' beliefs that pre-k teachers: (a) are excluded from quality PL; (b) have specific PL needs that are unique to their contexts; and (c) enjoy and grow as teachers from appropriate PL opportunities. In vivo quotes from the qualitative data represent the themes.

\section{"Not Geared for Us"}

When asked to describe recent experiences with PL, five participants immediately described instances where they felt excluded from engaging in quality PL offered by the school district. Melanie, a teacher in her 6th year, explained,

Most professional learning experiences ... that we've attended, are not always geared for pre-k, and we have to attend them, but the data or whatever is given doesn't include us. Most of the professional learnings are normally not geared towards pre-k unless it's actually given to us from the pre-k [department] itself.

Melanie further described how attending PL when student achievement data were reviewed was an additional source of discouragement for pre-k teachers. She stated,

They gave the data at the beginning of the year and gave the credit towards the kindergarten [teachers], but it should have been more so for pre-k, because it came from us. They get the praise for it, but the beginning of the year is what they learned at the end of the year from the previous year.

In addition to the observation that pre-k data and even mention of pre-k teachers were excluded from district-led PL, making it irrelevant to their instruction, Harriett, a teacher with 7 years of experience, described a lack of differentiation in department-led PL:
If we do have something geared for us, it's a repeat. It's the same thing over and over and over and over again... I understand they need [to do] it for new teachers coming in, but for those of us that have been here three to sixteen, and in Ms. ___ 's case, twenty-some years, it's just like, oh, this is a waste of my day.

Four new teachers described how they felt overlooked and overwhelmed with erroneous information from the start of their careers as pre-k teachers when they attended district-wide training for new teachers. Shannon, a teacher new to pre-k in the district, explained:

I went to [County] inductee training, and it was a whole week of training. They gave information about the county and what the requirements and what different entities are that they have. However, they didn't have like a special session for pre-k or it wasn't planned. And me being a new teacher coming, not a new teacher off the block, but a new teacher coming into [County], it was just like 'Whoa, it's a lot of information.'

Noticing that pre-k was simply excluded or skipped over altogether during instructional PL, data mining, and induction training fostered a sense that pre-k teachers were not equal parts of the educational community and that their contributions to student learning were ignored. Furthermore, repetition of training for all pre-k teachers without differentiation reinforced the feeling that PL was not truly "geared" for all of the pre-k teachers' growth as teachers.

\section{"It's Between a Rock and a Hard Place"}

While participants articulated feelings of exclusion from many PL opportunities, they also acknowledged times 
when they were offered quality, relevant PL through with the district. Also, because pre-k in the state was funded and operated under the state department of education (DOE), pre-k teachers had opportunities to take part in DOE-sponsored PL that was required for program certification. Engagement with both district-sponsored and DOE-sponsored PL created some conflict for the teachers when it was time to implement what they had learned. Melanie explained the conflict teachers sometimes experienced as they juggled incorporating instructional practices learned through district PL while also complying with state DOE early learning standards and expectations:

You learn things in training, however, you have these standards called _______ and you have these rules [State Early Learning Program] that they say that you can't do, but then you learn it in the training and they ask you to implement it.

And then you have someone that comes into your classroom to say, 'Well, we taught this to your teachers.' And they're telling the principal that they're not implemented. We can't implement it, because these things says that we can't! And it's just like it's between a rock and a hard place, because we want to do it, but they have stipulations.

Like ditto sheets for example, we can't do ditto sheets. And some instances I understand why we shouldn't, but in some instances it's okay. Coloring is, O KAY. So, I really feel that when you go to some of these trainings, and we learn so much and we're so excited about it, and we want to go back to the classroom and do these things, and then when we actually do some of them, and you have a consultant or someone that comes into the classroom to say, 'You shouldn't be doing that.'

'Well, I went to this professional learning and this is what I was taught to do.'

And then you get knocked down, and that kind of knocks us out from wanting to go to more professional learning, or not even wanting to do any of the things that we learn, because it gets knocked out.

In addition to conflicting expectations for pre-k instruction between district and state, the unique nature of pre-k required teachers to gather regionally within the state to participate in DOE-sponsored PL. "It's always been really, really very good training" stated Angela, a veteran pre-k teacher with 14 years of experience including 4th grade and special education, describing DOE-sponsored pre-k PL. She continued,
I just don't like to travel. I've had to drive four hours. I've had to drive three hours. And I just don't like to travel that far....Yeah, we have to go, we go all different places, and they have to pay for two nights at the hotel. But that's my opinion. Some people like to travel, but I don't. I'd like to be given the opportunity to do it locally. I feel like it would be more cost effective.

Florence, a 4th year pre-k teacher added, “I don't mind going to the trainings, but I'm one who doesn't like missing time from work or from my kids."

DOE-sponsored early learning PL opportunities were available for pre-k teachers. Although local PL opportunities eliminated the necessity for travel, there was another barrier for the teachers. Nell, another veteran teacher with 16 years of experience in pre-k, shared with the group,

I'd just like to say that [State Early Learning Program] does offer training locally here in [County], but typically by the time our county gets to filling us into those slots, the other entities have all, daycares or other counties nearby waiting on them, have filled all those slots. But they do offer training here, in the local area.

In addition to the conflicting responsibilities and expectations pre-k teachers faced within the district and state, participants described ways that their work was further complicated by the high-need contexts in which they taught. Children in their classrooms often came to pre-k without having had formal educational experiences and might be living in households where caregivers had not had previous or positive experiences engaging with teachers and schools. These situations meant that the teachers were not only introducing curriculum to their students, but they might be introducing them to the behavioral expectations of formal schooling.

Harriet described how the mismatch between some PL content and her work with high-need students left her struggling to balance the things she learned during PL. She explained:

They do discuss behavior, how to deal with children with behavior issues, but to really give us solid strategies and how to incorporate the parents, it's like, you're telling us, but is it really geared to our inner-city school children?... They really don't help, because we are sitting here like, okay, yeah, come in my room for a day.

Specifically addressing PL related to enriching student interactions through elaboration on children's response, Harriet explained the challenge of always prioritizing meaningful interactions with her students. 
Like the room presenter was saying, you're talking about a snowflake, and they're [children] talking about a brown bear. That is all the time! And so how to bring them back in if you let one talk about that brown bear, and you're trying to understand what's the connection piece to it?

In addition to working with a large number of children who were new to formal schooling, three teachers brought up her team's experiences working with children with unidentified special needs. Olivia, a pre-k teacher with 8 years of experience, described the work of the team of 3 pre-k teachers at her school.

So we are dealing with so many behavior issues, but we're not getting the immediate help that I think we should get in the classroom when we have 3 or 4 kids with a disability or a behavior problem.

We do all this paperwork the entire year, and they are not getting any help during pre-k. The help comes the next year when they'll get some assistance when they are in kindergarten. But, I think they need the assistance in pre-k, because it doesn't go anywhere. If we get the help then, then maybe some things that we can see can be helped before they move on to the next grade.

The special context of working with very young children in high-need schools along with conflicting expectations between district and state and PL opportunities limited by logistics and availability dominated participants PL experiences.

\section{"It Felt Good to Be Included"}

Although many of the teachers described experiencing feelings of exclusion and conflict within their PL experiences, they also expressed appreciation for times when they felt included and acknowledged with PL that was relevant and responsive to their unique instructional and contextual needs. Talia, a 3rd year teacher in the district with 17 years of experience teaching in early childhood, commented on her post-conference evaluation, "It felt good to be included with pre-k. I've attended trainings before but felt left out, because there was no pre-k information."

Participants identified developmentally appropriate instructional practices and topics in response to survey questions asking for recommendations for future conference activities. These topics of interest were used by district and university faculty to plan conference PL, and teachers described ways the PL had impacted their instructional practices. Participants in both interviews specifically described using make-and-take resources from the 2018 conference including a dog and bowl ABC activity, a miniature car Elkonin box activity, and a story-retelling visual. Olivia described one conference presentation on engaging read alouds and its impact on her team's instruction:

She [the presenter] had a room full of umbrellas. So, that just kind of gave me a light bulb of things to use other than the traditional reading. I know we all don't sit and just read a book, we like to act it out to have the kids involved using something. I think that helped us open up what we already had inside and just use things, bring things from home, and get kids much more engaged in reading. You may change our voice to sound like mom or dad, but it's not the same unless you having other manipulative things to help engage.

The 2019 conference PL activities were designed in response to 2018 participant feedback. Integrating science and social studies content through pairing of fiction and nonfiction texts and then aligning related activities with the state early learning standards were the goals of the 2019 PL. Two teachers specifically shared the names of the paired texts and recalled that the PL was engaging. Harriett explained how the literacy presentations during the conference pre-k strand supported her instructional challenges:

I struggle with trying to connect activities to the actual [state learning standard]. I'm dealing with literacy. I'm dealing with math. We have a curriculum, but you still have to tie in activities. So, due to the training, we can tie activities to the actual standard, especially for science and social studies.

Early writing support was also a focus of the 2019 conference, and a chorus of teachers agreed that the classroom mailbox and supplies (envelopes, paper, pencils, play stamps) they received during the conference were used heavily in their classrooms. Nelia stated,

I would like to say I absolutely love, love, love the mailbox that I received from the training last year. Because it has improved my kids' writing skills, communication skills, and it's just pretty much improved skills across the board. I'll see them independently go on the mailboxes. They're making sure that they're putting the stamps in the correct place, because we talked about all of that, so I'm just... I just love, love, loved those ideas.

In addition to specific topics and strategies that participants felt were supportive of their instruction, they also valued PL experiences where supplies necessary to implementing the things were provided. Four teachers pointed out that that personally paid for printing (printer, ink, and paper) and cleaning supplies on a weekly basis. Florence explained, 
Today is great, because you're showing us, and you've given us [supplies], but we don't always receive all of the materials and it's like, 'Ooh, oh, wow, this is so exciting!' But then your balloon is getting deflated, because, 'Where am I going to get the money to buy this?' So, that's one of the barriers. The materials. Coming back [to classroom], if you want to do the activities, just having the materials handy.

Having taught in K-5 classrooms, Angela, had a unique perspective on the importance of providing materials during PL for pre-k teachers. She stated,

...like you said, materials. You want to do all this stuff, but then you have to go out and buy it. That's a huge expense. I spend more money in pre-k than I ever have, and I get paid less than the other grades. [crosstalk in agreement] So, I spent more money in pre-k than I have in any... I taught fourth grade, and I taught SPED but I've spent more money on this classroom...

Participants articulated feeling included in PL when the learning was designed to meet the unique contextual needs of their classrooms including the developmental needs of their young students as well as the financial implications of providing for those needs.

\section{Discussion}

This study explored the efficacy beliefs, professional learning experiences, and literacy instructional practices of pre-k teachers from one high-need school district who engaged in a university-school PL collaboration. The results suggest that participants had strong and consistent efficacy beliefs related to their abilities to manage their classrooms and students. In addition, classroom observations confirmed the teachers' self-assessments of their strengths and weaknesses in the area of literacy instruction. Qualitative data addressed PL experiences and highlighted the teachers' perceived challenges, need for PL that was responsive to their unique contexts, and willingness to incorporate literacy instructional practices supportive of their students' learning needs.

\section{Strong and Consistent Efficacy Beliefs}

Self-efficacy, or a feeling of agency, is key to teachers' abilities to teach at the highest levels and to persist in challenging school contexts (Parejes, 2009; Tschannon-Moran $\&$ Woolfolk Hoy, 2001). We found that for the returning teachers, efficacy ratings across the two years were strongly correlated. Although efficacy beliefs on specific items fluctuated, self-efficacy of use of instructional strategies improved over the year. This finding is encouraging, since teaching efficacy and teaching performance are strongly associated in the related literature, and efficacy in instructional practices is also associated with teachers' job satisfaction (Klassen \& Tze, 2014; Tschannon-Moran \& Woolfolk Hoy, 2001) and commitment to teaching (Chesnut \& Burley, 2015). This finding is also positive considering the university-district partnership goal to support early learners by boosting their teachers' instructional skills. Participants were poised to become the effective teachers necessary for high-quality pre-k experiences (Farran, 2020).

\section{Desire for Relevant and Rigorous PL}

Quantitative and qualitative data in this study confirmed that participants felt they had classroom structures and environments that supported early literacy learning. Likewise, participants' relatively weaker feelings of efficacy regarding instructional practices were confirmed by the observational data. Participants accurately identified their strengths and challenges as well as their PL needs. Furthermore, focus group data confirmed that participants had indeed "felt left out" when it came to PL in their district, confirming information from district personnel who collaborated with the university on the PL.

While they recognized ways they were excluded from many PL opportunities, participants valued PL and desired to grow as educators. Participants described a variety of PL situations in which they had participated despite the fact that they were logistically challenging and sometimes led to knowledge that they were not able to implement due to DOE guidelines In fact, participants felt that their PL needs were so unique that delivery would be most effective if presented by one of their own exemplary colleagues or at least by a person with pre-k teaching experience. The PL our participants desired would have been grounded in collaboration with pre-k experts with a focus on engagement of children in learning, features of PL that Guo et al. (2011) found to be supportive of teacher efficacy.

In addition, consideration of the specific teaching context must be counted into the planning and delivery of effective PL. Participants in this study were consistent and clear in describing their "thinking, feeling and wanting" when it came to PL for supporting pre-k teachers.

\section{Classroom Literacy Practices}

Qualitative data collected through post-conference surveys, observations, and focus group interviews demonstrated that participants' classrooms during literacy instruction align with the efficacy findings. This aspect of the study is important, since teachers' self-reported efficacy is a complex construct that must be examined from multiple perspectives (Wheatley, 2005; Zee \& Koomen, 2016). Participants found 
PL related to Language Environment (hands-on phonics); Books and Book Reading (read-alouds), and Print and Early Writing (emergent writing) to be the most beneficial topics for supporting their teaching. Ideas for future PL topics were related to the two categories: Language Environment and Print and Early Literacy (additional literacy strategies and support for integrating literacy into the state learning standards). Participants consistently emphasized the need for additional PL for their instructional effectiveness, and this need was confirmed by the observational data that was collected.

\section{Significance of the Study}

This study reports research on a project to develop collaborative and targeted PL for pre-k teachers in a high-need school district. Korthagen (2017) argues, "if we wish to promote teacher learning, we will have to take their thinking, feeling and wanting into account" (p. 391). We endeavored to understand the "thinking, feeling and wanting" of this group of pre-k teachers and then to respond to what we learned through three consecutive years of PL to meet the district goals of improving literacy instruction. Burchinal and Farran (2020) argue that despite agreement on the importance of early learning, particularly for underserved children, and massive expenditures on teacher professional learning, evidence for effectiveness is lacking.

We gathered evidence about our participants' experiences with feelings of efficacy, experiences with professional learning, and instructional practices to learn whether our collaborative PL was effective. The qualitative data collected in this study served to include our participants in telling their stories. Ryan (2020) argues that "qualitative studies examining implementation of early childhood programs can provide practical information to help policymakers and leaders understand why early childhood programs do or do not fulfill their promise" (p. 261). While we studied a small group of pre-k teachers in one school district, Ryan (2020) argues that understanding the influences of the "local and contextual" on early learning outcomes is imperative for effective implementation (p. 261).

Our study may reveal opportunities for other schooluniversity partners to leverage existing PL events and for building collaborative PL relationships that support high quality instruction for early learners. Given the vital role that pre-k teacher quality has on student learning and the fact that the occupation of preschool teachers is projected to grow faster than all other occupations in the next five years (U.S. Department of Labor Bureau of Labor Statistics, 2020), not just including, but warmly welcoming pre-k teachers into effective professional learning experiences must be a priority.

\section{Limitations}

There are limitations of our study due to the limited sample size and the fact that our participant pool was limited to pre-k teachers in the school district who elected to attend the PL conference. Self-efficacy data were gathered through self-report and in an environment (the educational conference) where participant responses might have been influenced. Also limiting to our research was the fact that language and literacy environment data were based on one classroom observation of participants following their first year of attendance at the conference. We understand that these observations were snapshots in time across a school year that need to be repeated in order to learn more about the long-term impact of the PL. Finally, the 2020 conference took place less than one month from the abrupt interruption to school operations due to the COVID-19 pandemic, and this prohibited us from conducting classroom observations on the new participant teachers from the 2020 conference.

Supplementary Information The online version contains supplementary material available at https://doi.org/10.1007/s10643-021-01175-4.

\section{References}

Bandura, A. (1977). Self-efficacy: Toward a unifying theory of behavioral change. Psychological Review, 84, 191-215.

Bandura, A. (1997). Self-efficacy: The exercise of control. W. H. Freeman and Company.

Burchinal, M. (2018). Measuring early care and education quality. Child Development Perspectives, 12(1), 3-9. https://doi.org/10. 1111/cdep. 12260

Burchinal, M. C., \& Farran, D. C. (2020). What does research tell us about ECE programs? In Foundation for Child Development, Getting It Right: Using Implementation Research to Improve Outcomes in Early Care and Education, 13-36. Retrieved March 19, 2021 from https://www.fcd-us.org/assets/2020/06/GettingitR ight_UsingImplementationResearchtoImproveOutcomesinECE_ 2020.pdf

Chesnut, S., \& Burley, H. (2015). Self-efficacy as a predictor of commitment to the teaching profession: A meta-analysis. Educational Research Review, 15, 1-16.

Cohen, J. (1988). Statistical power analysis for the behavioral sciences (2nd ed.). Lawrence Erlbaum.

Creswell, J. W. (2013). Qualitative inquiry and research design: Choosing among five approaches (3rd ed.). SAGE Publications.

Eadie, P., Stark, H., \& Frank, N. (2019). Quality of interactions by early childhood educators following a language-specific professional learning program. Early Childhood Education Journal, 47(3), 251-263. https://doi.org/10.1007/s10643-019-00929-5

Farran, D. (2020). Making prekindergarten classrooms better places for children's development. In Foundation for Child Development, Getting it Right: Using Implementation Research to Improve Outcomes in Early Care and Education, 89-108. Retrieved March 19, 2021 from https://www.fcd-us.org/assets/2020/06/GettingitR ight_UsingImplementationResearchtoImproveOutcomesinECE_ 2020.pdf 
Guo, Y., Justice, L., Sawyer, B., \& Tompkins, V. (2011). Exploring factors related to preschool teachers' self-efficacy. Teaching and Teacher Education, 27(5), 961-968.

Heckman, J. J. (2011). The economics of inequality: The value of early childhood education. American Educator, 35(1), 31-35.

Klassen, R. M., Bong, M., Usher, E. L., Chong, W. H., Huan, V. S., Wong, I. Y. F., \& Georgiou, T. (2009). Exploring the validity of a teachers' self-efficacy scale in five countries. Contemporary Educational Psychology, 34(1), 67-76.

Klassen, R., \& Tze, V. (2014). Teachers' self-efficacy, personality, and teaching effectiveness: A meta-analysis. Educational Research Review, 12, 59-76.

Korthagen, F. (2017). Inconvenient truths about teacher learning: Towards professional development 30. Teachers and Teaching, 23(4), 387-405.

Pajares, F. (1996). Self-efficacy beliefs in academic settings. Review of Educational Research, 66, 543-578.

Pajares, F. (2009). Motivational role of self-efficacy beliefs in selfregulated learning. In: D. H. Pianta, R., \& Hamre, B. (2020). Improving quality and impact through workforce development and implementation systems. In Foundation for Child Development, Getting it Right: Using Implementation Research to Improve Outcomes in Early Care and Education, 109-130. Retrieved March 19, 2021 from https://www.fcd-us.org/assets/2020/06/GettingitR ight_UsingImplementationResearchtoImproveOutcomesinECE_ 2020.pdf.

Pianta, R. \& Hamre, B. (2020). Improving quality and impact through workforce development and implementation systems. In Foundation for Child Development, Getting It Right: Using Implementation Research to Improve Outcomes in Early Care and Education, 109-130. Retrieved March 19, 2021 from https://www.fcd-us.org/ assets/2020/06/GettingitRight_UsingImplementationResearchtoI mproveOutcomesinECE_2020.pdf.

Ryan, S. (2020). The contributions of qualitative research to understanding implementation of early childhood policies and programs. In Foundation for Child Development, Getting it Right:
Using Implementation Research to Improve Outcomes in Early Care and Education, 259-274. Retrieved March 19, 2021 from https://www.fcd-us.org/assets/2020/06/GettingitRight_Using ImplementationResearchtoImproveOutcomesinECE_2020.pdf

Smith, M. W., Brady, J. P., \& Anastasopoulos, L. (2012). 2012 Addendum to the technical appendix: User's guide to the early language and literacy classroom observation. Paul H. Brooks Publishing Co.

Smith, M. W., Dickinson, D. K., Sangeorge, A., \& Anastasopoulos, L. (2002). Early language and literacy classroom observation toolkit: Research edition. Paul H. Brookes Publishing Co.

Tschannen-Moran, M., Hoy, A. W., \& Hoy, W. K. (1998). Teacher efficacy: Its meaning and measure. Review of Educational Research, 68(2), 202-248.

Tschannen-Moran, M., \& Woolfolk Hoy, A. (2001). Teacher efficacy: Capturing an elusive construct. Teaching and Teacher Education, 17, 783-805.

Tschannen-Moran, M., \& Woolfolk Hoy, A. (2007). The differential antecedents of self-efficacy beliefs of novice and experienced teachers. Teaching and Teacher Education, 23(6), 944-956.

U.S. Department of Labor Bureau of Labor Statistics. (2020). Occupational Outlook Handbook: Preschool Teachers. https://www.bls. gov/ooh/education-training-and-library/preschool-teachers.htm

Wheatley, K. (2005). The case for reconceptualizing teacher efficacy research. Teaching and Teacher Education, 21(7), 747-766.

Zee, M., \& Koomen, H. M. (2016). Teacher self-efficacy and its effects on classroom processes, student academic adjustment, and teacher well-being: A synthesis of 40 years of research. Review of Educational Research, 86(4), 981-1015.

Publisher's Note Springer Nature remains neutral with regard to jurisdictional claims in published maps and institutional affiliations. 